\title{
Interleukin-10 (1082G/A) Polymorphism is Associated with Susceptibility of Acute Myeloid Leukemia Patients in Sudanese Population
}

\author{
Omnia Mohamed Sharif ${ }^{1}$, Rosline Hassan², Ameen Abdulaziz Mohammed \\ Basbaeen $^{3}$, Ayman Hussien Mohmed ${ }^{4}$, Ibrahim Khider Ibrahim ${ }^{2,3 *}$
}

\begin{abstract}
Background: Interleukin-10 (IL-10) is a multifunctional cytokine with both immunosuppressive and antiangiogenicfunctions and may have both tumor-promoting and -inhibiting properties. We examined the association between a single nucleotide polymorphism (SNP) in $I L-10-1082 G / A$ (rs 1800896) in Sudanese acute myeloid leukemia (AML) patients and to assess the association between polymorphisms in IL-10 -1082G/A (rs1800896) and the hematological profile in Sudanese patients with AML. Methods: A total of 30 patients with acute myeloid leukemia and 30 control subjects were enrolled in this study. Blood samples were collected from all patients in EDTA containing tubes. Genomic DNA was extracted from all blood samples using salting out method. The genotypic variants of IL-10 (-1082G/A) polymorphism were detected by allele specific-PCR. Results: We found that (36.7\%) of patients have homogenous GG genotype, (43.3\%) have heterogeneous GA genotype and (20.0\%) have AA genotype. GA genotype was significantly associated with higher risk of AML compared with the homozygous Genotypes (GG and AA), there is no association between $I L-10(-1082 \mathrm{G} / \mathrm{A})$ polymorphism and AML sub-type, gender, age group, mean of hematological parameters. Conclusion: Our study concluded that GA genotype of $I L-10-1082 G / A$ ( $r s 1800896)$ polymorphism is a risk factor for AML and G allele is insignificantly higher than A allele in AML patient. No association between $I L-10$ $(-1082 G / A)$ polymorphism and AML sub-type, gender, age group, mean of hematological parameters.
\end{abstract}

Keywords: Interleukin-10- polymorphism- acute myeloid leukemia

Asian Pac J Cancer Prev, 20 (7), 1939-1943

\section{Introduction}

Acute leukemia comprises acute lymphoblastic leukemia (ALL) and acute myeloid leukemia (AML) (Mandegary et al., 2011). Adults have more risk than children to have AML, it is the most common type of acute leukemia affecting adults (Jiang et al., 2011). The etiology of AML is complicated and not fully understood. Numerous factors are thought to play an important role in AML development, for instance chemical exposure, ionizing radiation, and genetics (Evans and Steward, 1972; Le Beau et al., 1986).

Interleukins (ILs) are a varied set of small cells signaling protein molecules, or cytokines, their function is to alter the immune system in humans, ILs are predominantly produced by antigen-presenting cells, monocytes, macrophages, and endothelial cells, which are involved in the regulation of immune cell responses against infections, as well as governing the inflammation, differentiation, proliferation, and secretion of antibodies for tumor development (Fei et al., 2015). Single nucleotide polymorphisms (SNPs) of ILs may alter their function, thus changing cytokine function and dysregulating their expression (Fei et al., 2015).

Interleukin-10 (IL-10) is a multifunctional cytokine with both immunosuppressive and anti-angiogenic functions and may have both tumor promoting and inhibiting properties (Howell and Rose-Zerilli, 2006).

The gene encoding $I L-10$ is located on human chromosome 1, between 1q31 and 1q32 (Eskdale et al., 1997). Many SNPs have been distinguished within the cytokine gene sequence, particularly within the promoter regions, including $I L 10-1082 A / G$ ( $r s 1800870)$, $-819 C / T$ (rs 1800871) and -592A/C (rs1800872). These polymorphisms may be associated with differential levels of gene transcription, since some alleles can produce low,

${ }^{1}$ Department of Haematology, Faculty of Medical Laboratory Sciences, Sudan University of Science and Technology, ${ }^{3}$ Department of Haematology, Faculty of Medical Laboratory Sciences, Al Neelain University, Khartoum, Sudan, '2Department of Hematology, School of Medical Sciences, University Sains Malaysia, Health Campus, 16150 Kubang Kerian, Kelantan, Malaysia, ${ }^{4}$ Hematology and Blood Banking Unit, Medical Laboratory Technology Department, Jazan University, Jazan, KSA. *For Correspondence: ibrahimkh82@gmail.com 
medium and high amounts of $I L-10$ (Eskdale et al., 1997). The capability to secrete different cytokines appears to be significant in the immune response (Hutchinson et al., 1999). Genetic studies have been conducted to associate these cytokine polymorphisms with some types of cancer, but with varied results (Stanczuk et al., 2001; Roh et al., 2002; Szöke et al., 2004; Matsumoto et al., 2010).

To the best of our knowledge this is the first study conducted in Sudan to investigate the association between the $I L-10(1082 G / A)$ polymorphism in AML patients and correlated with some hematological parameters.

So the main goal of this study is to examine the genotype frequency of $I L-10(1082 \mathrm{G} / \mathrm{A})$ polymorphism and exploring association between $I L-10(1082 G / A)$ polymorphism and Risk of Acute Myeloid Leukemia, Furthermore, to assess correlation between $I L-10(1082 G / A)$ polymorphism and some hematological parameter among Sudanese patients with Acute Myeloid Leukemia.

\section{Materials and Methods}

\section{Study Population}

In this is case-control study a total of 30 newly diagnosed AML patients were recruited at the Radio isotope center Khartoum (RICK) Sudan in the period from January to May 2017. AML diagnosis was determined according to World Health Organization criteria based on an increased number of myeloblasts in the bone marrow or peripheral blood (Vardiman et al., 2002). Patients with a history of cancer, known blood disorders, diabetes, and connective tissue disease were excluded from the study. Additionally, 30 age and gender-matched apparently healthy control subjects were recruited to participate in the study.

\section{Sample collection}

A venous blood sample (Three $\mathrm{ml}$ ) was taken from each participant; these samples were collected into a tube containing $\mathrm{K}+$ ethylene diamine tetra acetic acid (EDTA).

\section{Determination of Complete Blood Counts and Immunophenotype}

Complete blood count was analyzed by using automated hematology analyzer (SYSMMEX KX-21N, Japan) within 6-24h from the collection. All results such total white blood cell (WBC) count, Hemoglobin $(\mathrm{Hb})$ concentration and platelets count were recorded. And a blood smear stained by May Grunwald Giemsa was obtained for all patients. The diagnosis of AML was confirmed by Flow Cytometery, according to the standard procedure of diagnosis AML at Radio isotope at Radio Isotopes Center Khartoum (RICK) in Sudan (Osman et al., 2015). A marker was considered positive is a result $\geq 20 \%$ (Osman et al., 2015).

\section{DNA extraction}

Genomic DNA was extracted by salting out method(Miller et al., 1988). To assess the DNA quality after DNA extraction, the $\beta$-globin gene amplification was used to evaluate the quality of DNA in all extracted samples, as previously described (Kerr et al., 2000).
All specimens for $\beta$-globin gene were Successful amplification, [Primers shown in Table1]. To evaluate the DNA quantification after DNA extraction, we measured DNA by using a NanoDrop spectrophotometer. Then DNA samples were routinely stored at $-20^{\circ} \mathrm{C}$.

\section{Genotyping of IL-10(1082G/A)}

Genotyping was carried out by using the polymerase chain reaction with allele specific primers as described by (Newton et al., 1989). The primer sequences for genotyping are shown in (Table 1). Two separated PCR reaction mixtures of $20 \mu 1$ was prepared for each sample. PCR was performed by using Maxime PCR Premix Kit (i-Taq), (iNtRON BIOTECHNOLOGY, SouthKorea), Cat. No. 25025), $4 \mu 1$ of genomic DNA, $0.5 \mu 1$ of each primer, and $14 \mu 1$ distilled water. Beta globin gene was used as the internal control. PCR started at $94^{\circ} \mathrm{C}$ for $5 \mathrm{~min}$, followed by denaturation at $94^{\circ} \mathrm{C}$ for $30 \mathrm{~s}$, annealing at $58^{\circ} \mathrm{C}$ for 30 $\mathrm{s}$, and extension at $72^{\circ} \mathrm{C}$ for $40 \mathrm{~s}$, with a final extension at $72^{\circ} \mathrm{C}$ for $5 \mathrm{~min}$. Thermo cycling was using TECHNE Tc-412-UK PCR Thermal Cycler 96 well.

The amplified products were run on $1.5 \%$ agarose gel, and then stained with ethidium bromide for visualization under ultraviolet gel documentation system (See Figure 1).

\section{Statistical analysis}

All statistical analyses were performed using the SPSS 16.0 software. Chi square was done to determine the association and risk factor.

Gel electrophoresis showing $I L-10$ SNPs: Lane L: DNA marker (Ladder 100bp). Lanes 1, 2, 3, 4: heterozygous $(\mathrm{A} / \mathrm{G})$. Lanes 5 , 6: homozygous $(\mathrm{G} / \mathrm{G})$. Lanes 7, 8: homozygous (A/A). Both alleles produce same size product $550 \mathrm{bp}$.

\section{Results}

\section{Characteristics of 30 patients with Acute Myeloid} Leukemia

In this study, 30 cases of AML were targeted, the overall mean age was $(20.23 \pm 10.24)$ with range $(3-37 y)$. AML, however, is the most common in adults $21(70.0 \%)$. Fourteen $(46.6 \%)$ were males while sixteen $(53.4 \%)$ were females; Male to female ratio was (0.9:1). The AML-M3was the most frequent 11(36.6\%), followed by AML-M4 7(23.3\%), whereas AML-M7was the least frequent $1(3.3 \%)$. Regarding means white blood cell count was $39.14 \pm 60.31 \times 10^{3} /$ ul, hemoglobin level was $8.67 \pm 2.51 \mathrm{~g} / \mathrm{dL}$, platelet count was $93.33 \pm 134.66 \times 10^{3} /$ ul and peripheral blast percentage was $60.63 \pm 21.01 \%$.

\section{IL-10 gene polymorphisms and AML}

The genotype and allele frequencies for both patients and controls are listed in (Table 2), showing a highly statistically significant difference in the genotype distribution between cases and controls. GA genotype prevalence were significantly higher in cases than in controls $13,43.4 \%$ vs. $3,10 \%, \mathrm{P}=0.003$ respectively. On the other hand, AA genotype prevalence were higher among controls than in AML patients $16(53.3 \%)$ vs $6(20$ $\%), \mathrm{P}=0.007$, respectively. IL-10-(1082G/A) $(\mathrm{GA}+\mathrm{GG})$ 
Table 1. The Primers Sequence for $I L-10-1082 A / G$ Polymorphism Used were as Follow

\begin{tabular}{llc}
\hline Primers & Sequence & Product size $(\mathrm{bp})$ \\
\hline$I L-10$ A Allele & 5'-CTACTAAGGCTTCTTTGGGAA-3' & $550 \mathrm{bp}$ \\
$I L-10$ G Allele & 5'-TACTAAGGCTTCTTTGGGAG-3' & \\
IL-10 common & 5'-CAGCCCTTCCATTTTACTTTC-3' \\
$\beta$ globin-GH20 (Forward) & 5'-GAAGAGCCAAGGACAGGTAC-3' & $268 \mathrm{bp}$ \\
$\beta$ globin-PC04 (Reverse) & 5'-CAACTTCATCCACGTTCACC-3' \\
\hline
\end{tabular}

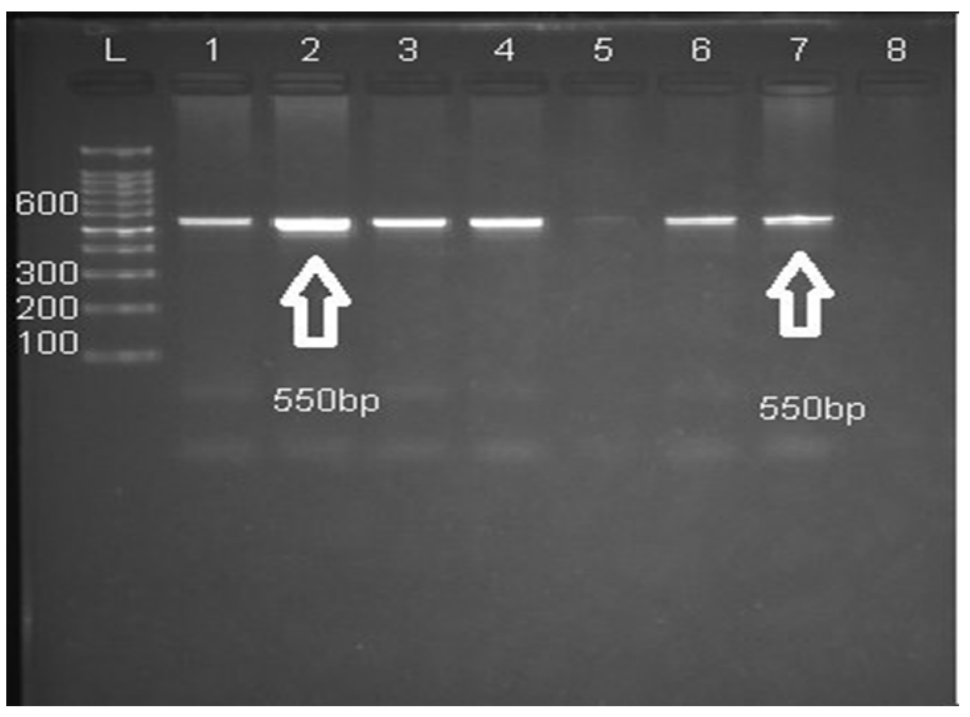

Figure 1. It Shows the Sized Amplicons Outcome of AS-PCR

genotype was increased risk of AML and there was a statistically significant correlation between GA genotype and AML risk.

No statistically significant association found between any of $I L-10$ genotypes and age, gender, total leucocyte count, $\mathrm{Hb}$ concentration, Platelets count, Blast percentage and FAB subtypes $(\mathrm{P}>0.05)$.

\section{Discussion}

In this cross-sectional descriptive study, 30 cases of AML were studied, the overall mean age was
(20.23 \pm 10.24$)$ with range $(3-37 y)$. AML is the most common in adults $21(70.0 \%)$. Nearly similar reported that found in literature (Ghosh et al., 2003; Estey and Döhner, 2006; Noronha et al., 2011; Osman et al., 2015).

The mean age of our patients with AML, was lower than the patients with AML in developed countries (Chang et al., 2004; Al-Mawali et al., 2008), but it was similar to other studies that performed in developing countries (Bittencourt et al., 2003; Ghosh et al., 2003; Rego et al., 2003; Osman et al., 2015). This can be explained by the fact that, in developed countries, life expectancy is higher and elderly individuals constitute a greater proportion of

Table 2. Distribution of Genotypes and Allele Frequencies of $I L-10$ ( $A-1082 G$ ) Polymorphism in Acute Myeloid Leukemia Patients and Controls

\begin{tabular}{|c|c|c|c|c|c|}
\hline Genotype & AML patients no (\%) & Controls no (\%) & P-value & Odd ratio & $(95 \% \mathrm{CI})$ \\
\hline \multicolumn{6}{|l|}{ Genotype } \\
\hline AA & $6(20 \%)$ & $16(53.3 \%)$ & 0.007 & 0.22 & $0.07-0.69$ \\
\hline GG & $11(36.6 \%)$ & $11(36.7 \%)$ & 1 & 1 & $0.35-2.86$ \\
\hline GA & $13(43.4 \%)$ & $3(10 \%)$ & 0.003 & 6.8 & $1.71-27.75$ \\
\hline Total & $30(100 \%)$ & $30(100 \%)$ & & & \\
\hline \multicolumn{6}{|l|}{ Combined } \\
\hline $\mathrm{GA}+\mathrm{GG}$ & $24(80 \%)$ & $14(46.6 \%)$ & 0.007 & 4.57 & $1.45-14.39$ \\
\hline AA & $6(20 \%)$ & $16(53.4 \%)$ & & & \\
\hline $\mathrm{AA}+\mathrm{GA}$ & $19(63.3 \%)$ & $19(63.3 \%)$ & 1 & 1 & $0.35-2.86$ \\
\hline GG & $11(36.7 \%)$ & $11(36.7)$ & & & \\
\hline \multicolumn{6}{|l|}{ Allele } \\
\hline A & $26(43.4 \%)$ & $32(60 \%)$ & & 0.67 & $0.33-1.37$ \\
\hline G & $34(56.6 \%)$ & $24(40 \%)$ & & & \\
\hline
\end{tabular}


the population.

Fourteen (46.6\%) were males while sixteen $(53.4 \%)$ were females; Male to female ratio was (0.9:1). our result nearly similar to previous report in Sudan, in addition it showed that there is no male predominance, the male to female ratio 1.3:1. In contrast, the most studies have found that a higher incidence of AML is males (Bittencourt et al., 2003; Ghosh et al., 2003; Rego et al., 2003; Osman et al., 2015), this discrepancy may be due to small size of our patients group.

Regarding AML subtype in our patients, AML-M3 was the most frequent 11(36.6\%), followed by AML-M4 7 (23.3\%), whileAML-M7 was the least frequent 1 (3.3\%). Osman et al., (2015) revealed that AML-M0 was the most common subtype. Whereas, Callera et al., (2006) explained that the higher prevalence of the AML subtype was AML-M1. Furthermore Ghosh et al., (2003), Pulcheri et al., (1995) and Bittencourt et al., (2003) found that a higher frequency of AML subtype was AML-M2.

In the recent years, a simple single nucleotide polymorphism arrays is efficient technique in order to detect genetic variation in malignant cell, including AML (Maciejewski et al., 2009).

IL-10 is avital immune-regulatory cytokine, which is produced by activated T cells, monocytes, B cells, and thymocytes. IL-10 has many functions including immuno-stimulating and immuno-suppressive functions, and it may well control tumor susceptibility and development (Helminen et al., 1999; Villalta et al., 2010).

According to this hypothesis, several studies have been performed in order to investigate the association of the $I L-10$ promoter polymorphisms with cancers. Polymorphisms in the promoter region of the IL-10 gene were related to cancer susceptibility, affected the severity, progression of the disease, and the level of IL-10 expression (Zhou et al., 2008; Chen et al., 2010).

For AML, only little studies stated an association between in interleukin-10 (IL-10) -1082G/A (rs1800896) gene polymorphisms and risk of AML (Chenjiao et al., 2013; Yao et al., 2013); these studies showed that polymorphisms in rs 1800871 and $r s 1800872$ could be associated with increased risk of AML and were correlated with $I L-10$ mRNA expression in AML patients. Likewise, we also reported an association between $1082 \mathrm{G} / \mathrm{A}$ (rs1800896), genetic variants and AML risk.

A study on the Chinese population presented that polymorphisms in interleukin-10 (rs 1800871 and rs 1800872) enhanced the susceptibility of AML, and these 2 SNPs had a synergistic effect on AML risk (Fei et al., 2015). A finding which is come to an agreement with our findings.

A study was done in Egypt (Rashed et al., 2018) and they did not find any association between $I L-10$ -819 T/C (rs 1800871) promoter polymorphism and clinicopathological data such as AML sub-type, gender, age group, mean of the hematological parameter (TWBCs, Blast $\%, \mathrm{Hb}$ and platelet count). A result which agrees with our findings.

In conclusions briefly, our study suggests that GA genotype of $I L-10-1082 G / A$ (rs 1800896) polymorphism is a risk factor for AML and G allele is insignificantly higher than A allele in AML patient. No association between $I L-10(-1082 G / A)$ polymorphism and AML sub-type, gender, age group, mean of the hematological parameters (TWBCs, Blast $\%, \mathrm{Hb}$ and platelet count).

\section{Acknowledgments}

We would like to thank the staff of Haematology Department at Al Neelain University for facilities and support and we are grateful to the staff of Radio Isotope Center Khartoum (RICK) for their collaboration. Finally, special thanks to the patients for being cooperative, despite their pain.

\section{Limitations}

Limitations which are worth to remark are: sampling method was rest on voluntary contribution and no bone marrow samples were obtained, patients were not tracked up for progression of AML, survival rates and response to therapy administered after diagnosis confirmation. The preceding limitations should be well thought-out in the interpretation of this study results.

\section{Authors' contributions}

OMS and IKI conceived the study design, participated in data collection, carried out the laboratory work, performed the statistical analysis, interpreted the results, and revised the manuscript. IKI, AAB and RH revised the manuscript. All authors read and approved the final manuscript.

\section{Author details}

Department of Haematology, Faculty of Medical Laboratory Sciences, Sudan University of Science and Technology, Khartoum, Sudan1. Department of Haematology, Faculty of Medical Laboratory Sciences, Al Neelain University, Khartoum, Sudan2. Department of Hematology, School of Medical Sciences, University Sains Malaysia, Health Campus, 16150 KubangKerian, Kelantan, Malaysia3.

\section{Competing interests}

The authors declare that they have no competing interests.

\section{Available of data and materials}

The individual data are available in the archives of Radio isotope center Khartoum (RICK), Sudan. And can be obtained from the corresponding author on request.

\section{Consent for Publication \\ Not applicable.}

\section{Ethics approval and consent to participate}

Ethical clearance was obtained from the Institutional Review Board at Al Neelain University. Principal investigator obtained written informed consent from all participants prior to their inclusion in the study.

\section{Funding}

This research did not receive any fund or financial 
support.

\section{References}

Al-Mawali A, Gillis D, Hissaria P, et al (2008). Incidence, sensitivity, and specificity of leukemia-associated phenotypes in acute myeloid leukemia using specific five-color multiparameter flow cytometry. Am J Clin Pathol, 129, 934-45.

Bittencourt R, Fogliato L, Daudt L, et al (2003). Leucemia Mielóide Aguda: perfil de duas décadas do Serviço de Hematologia do Hospital de Clínicas de Porto Alegre-RS. Rev Bras Hematol Hemoter, 25, 15-24.

Callera F, Mulin CC, Rosa ES, et al (2006). High prevalence of morphological subtype FAB M1 in adults with de novo acute myeloid leukemia in São José dos Campos, São Paulo. Sao Paulo Med J, 124, 45-7.

Chang H, Salma F, Yi Q-1, et al (2004). Prognostic relevance of immunophenotyping in 379 patients with acute myeloid leukemia. Leuk Res, 28, 43-8.

Chen K, Li B, Wei Y, et al (2010). Interleukin-10-819 promoter polymorphism associated with gastric cancer among Asians. $J$ Int Med Res, 38, 1-8.

Chenjiao Y, Zili F, Haibin C, et al (2013). IL-10 promoter polymorphisms affect $I L-10$ production and associate with susceptibility to acute myeloid leukemia. Die Pharmazie-An Int J Pharm Sci, 68, 201-6.

Eskdale J, Kube D, Tesch H, et al (1997). Mapping of the human IL10 gene and further characterization of the 5'flanking sequence. Immunogenetics, 46, 120-8.

Estey E, Döhner H (2006). Acute myeloid leukaemia. Lancet, 368, 1894-907.

Evans D, Steward J (1972). Down's syndrome and leukaemia. Lancet, 300, 1322.

Fei C, Yao X, Sun Y, et al (2015). Interleukin-10 polymorphisms associated with susceptibility to acute myeloid leukemia. Genet Mol Res, 14, 925-30.

Ghosh S, Shinde S, Kumaran G, et al (2003). Haematologic and immunophenotypic profile of acute myeloid leukemia: an experience of Tata Memorial Hospital. Indian J Cancer, 40, 71 .

Helminen M, Lahdenpohja N, Hurme M (1999). Polymorphism of the interleukin-10 gene is associated with susceptibility to Epstein-Barr virus infection. $J$ Infect Dis, 180, 496-9.

Howell WM, Rose-Zerilli MJ (2006). Interleukin-10 polymorphisms, cancer susceptibility and prognosis. Fam Cancer, 5, 143-9.

Hutchinson I, Pravica V, Hajeer A, et al (1999). Identification of high and low responders to allografts. Rev Immunogenet, 1, 323-33.

Jiang H, Lu Y, Yuan L, et al (2011). Regulation of interleukin-10 receptor ubiquitination and stability by beta-TrCP-containing ubiquitin E3 ligase. PLoS One, 6, e27464.

Kerr J, Al-Khattaf A, Barson A, et al (2000). An association between sudden infant death syndrome (SIDS) andHelicobacter pylori infection. Arch Dis Child, 83, 429-34.

Le Beau MM, Albain K, Larson R, et al (1986). Clinical and cytogenetic correlations in 63 patients with therapy-related myelodysplastic syndromes and acute nonlymphocytic leukemia: further evidence for characteristic abnormalities of chromosomes no. 5 and 7. J Clin Oncol, 4, 325-45.

Maciejewski JP, Tiu RV, O'Keefe C (2009). Application of array-based whole genome scanning technologies as a cytogenetic tool in haematological malignancies. $\mathrm{Br} J$ Haematol, 146, 479-88.

Mandegary A, Rostami S, Alimoghaddam K, et al (2011). Gluthatione-S-transferase T1-null genotype predisposes adults to acute promyelocytic leukemia; a case-control study. Asian Pac J Cancer Prev, 12, 1279-82.

Matsumoto K, Oki A, Satoh T, et al (2010). Interleukin-10- 1082 gene polymorphism and susceptibility to cervical cancer among Japanese women. Jpn J Clin Oncol, 40, 1113-6.

Miller S, Dykes D, Polesky H (1988). A simple salting out procedure for extracting DNA from human nucleated cells. Nucleic Acids Res, 16, 1215.

Newton C, Graham A, Heptinstall L, et al (1989). Analysis of any point mutation in DNA. The amplification refractory mutation system (ARMS). Nucleic Acids Res, 17, 2503-16.

Noronha EP, Marinho HT, Thomaz EBAF, et al (2011). Immunophenotypic characterization of acute leukemia at a public oncology reference center in Maranhão, northeastern Brazil. Sao Paulo Med J, 129, 392-401.

Osman IM, Humeida A, Eltayeb O, et al (2015). Flowcytometric Immunophenotypic characterization of acute myeloid leukemia (AML) in Sudan. Int J Hematol Dis, 2, 10-7.

Pulcheri W, Spector N, Nucci M, et al (1995). The treatment of acute myeloid leukemia in Brazil: progress and obstacles. Haematologica, 80, 130-5.

Rashed R, Shafik RE, Shafik NF, et al (2018). Associations of interleukin-10 gene polymorphisms with acute myeloid leukemia in human (Egypt). J Cancer Res Ther, 14, 1083.

Rego M, Pinheiro G, Metze K, et al (2003). Acute leukemias in Piauí: comparison with features observed in other regions of Brazil. Brazil J Med Biol Res, 36, 331-7.

Roh JW, Kim MH, Seo SS, et al (2002). Interleukin-10 promoter polymorphisms and cervical cancer risk in Korean women. Cancer Lett, 184, 57-63.

Stanczuk GA, Sibanda EN, Perrey C, et al (2001). Cancer of the uterine cervix may be significantly associated with a gene polymorphism coding for increased $I L-10$ production. Int $J$ Cancer, 94, 792-4.

Szöke K, Szalmás A, Szládek G, et al (2004). IL-10 promoter nt-1082A/G polymorphism and human papillomavirus infection in cytologic abnormalities of the uterine cervix. J Interferon Cytokine Res, 24, 245-51.

Vardiman JW, Harris NL, Brunning RD (2002). The World Health Organization (WHO) classification of the myeloid neoplasms. Blood, 100, 2292-302.

Villalta SA, Rinaldi C, Deng B, et al (2010). Interleukin-10 reduces the pathology of $\mathrm{mdx}$ muscular dystrophy by deactivating M1 macrophages and modulating macrophage phenotype. Hum Mol Genet, 20, 790-805.

Yao C-J, Du W, Chen H-B, et al (2013). Associations of $I L-10$ gene polymorphisms with acute myeloid leukemia in Hunan, China. Asian Pac J Cancer Prev, 14, 2439-42.

Zhou S, Zhu W, Li M, et al (2008). Association of single nucleotide polymorphism at interleukin-10 gene $1082 \mathrm{nt}$ with the risk of gastric cancer in Chinese population. Nan Fang Yi Ke Da Хие Хие Вао, 28, 1335-8.

\section{$\Theta(\Theta \otimes$}

This work is licensed under a Creative Commons AttributionNon Commercial 4.0 International License. 